\title{
Yeast Model System
}

National Cancer Institute

\section{Source}

National Cancer Institute. Yeast Model System. NCI Thesaurus. Code C19617.

Pathways and other molecular and cellular processes which can be manipulated in yeast, the results of which can be extrapolated to human systems. 